\title{
Commentary: Following the guidelines: Life in the real world
}

\author{
Donald D. Glower, MD
}

From the Division of Cardiothoracic Surgery, Department of Surgery, Duke University Medical Center, Durham, NC.

Disclosures: Author has nothing to disclose with regard to commercial support.

Received for publication Aug 15, 2018; accepted for publication Aug 17, 2018; available ahead of print Sept 20, 2018.

Address for reprints: Donald D. Glower, MD, Box 3851, Duke University Medical Center, Durham, NC 27710

(E-mail: Glowe001@mc.duke.edu).

J Thorac Cardiovasc Surg 2019;157:1442-3

$0022-5223 / \$ 36.00$

Copyright (c) 2018 by The American Association for Thoracic Surgery

https://doi.org/10.1016/j.jtcvs.2018.08.025

Hannan and colleagues ${ }^{1}$ provide unique insight into how the guidelines are being followed in the real world. The authors compared outcomes of isolated mitral repair versus replacement with chronic severe primary mitral valve regurgitation with preserved ventricular function and no heart failure symptoms from the New York State cardiac surgery registry. The authors conclude that in 854 matched patients, those who underwent mitral repair experienced lower mortality and no different reoperation or readmission rates than patients who underwent replacement, surgeons with a higher volume of operations were more likely than their lower-volume counterparts to choose mitral repair, and repair should be considered as the surgical option for these patients whenever possible.

The findings of different outcome from mitral repair versus replacement and the association of surgeon volume with likelihood of mitral repair are not new. The worse survival with mitral replacement versus repair seen here could result from selection bias, lack of chordal preservation during mitral replacement, or increased mortality from bleeding, thromboembolism, and pacemaker requirement with mitral replacement.

The new aspect of this study is that that these findings are demonstrated in patients with chronic severe primary (degenerative) mitral valve regurgitation with preserved ventricular function and no heart failure symptoms. These are the patients who by American College of Cardiology/ American Heart Association guidelines should only be undergoing surgery if their chances of receiving repair are at least $95 \%$. In fact, in this data set, only $79.9 \%$ received mitral repair. Even surgeons with a higher volume operating on more than 46 potentially repairable mitral valves per year had an $87 \%$ repair rate, well below the $95 \%$ recommendation.

Several factors could explain lower repair rates than expected. Asymptomatic patients with degenerative mitral valve regurgitation and surgeons may experience pressure to operate on less-repairable valves. Patients in this study

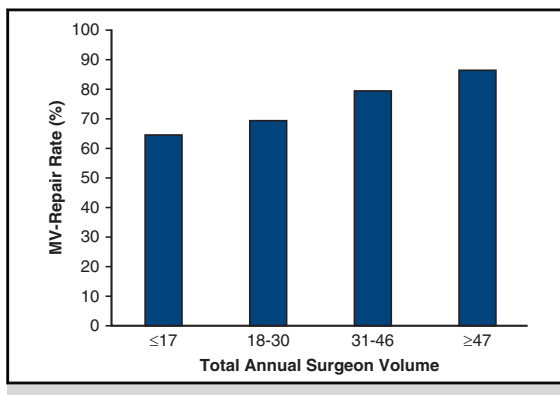

Percentage of all mitral valve procedures that are repairs by surgeon volume quartile.

\section{Central Message}

Asymptomatic patients with primary mitral regurgitation had a repair rate of only $79.9 \%$. This rate less than $95 \%$ could result from other indications to operate or difficulty predicting mitral repairability.

See Article page 1432.

may have had other indications to undergo operation, such as atrial fibrillation, end-systolic diameter greater than $4.0 \mathrm{~cm}$, pulmonary hypertension, or ejection fraction less than $60 \%$ without cardiomyopathy. Patients and surgeons might be concerned about data suggesting that late survival is less with wait and watch than with early surgery. $^{2}$ Finally, current technology (echocardiography) may not be sufficient to accurately predict mitral repairability. Lack of repairability often results from mitral fibrosis/calcification that can be difficult to appreciate on echocardiography. Moreover, current mitral valve assessment lacks a repairability scoring system like that used to judge suitability for balloon mitral valvuloplasty. ${ }^{3}$ Such a repairability scoring system could allow us to follow less-repairable valves longer than those likely repairable. Whether replacement valves should be followed longer than repairable valves is yet to be determined.

These retrospective registry data are by nature potentially flawed. Yet, the size of the data set and the very believable findings do have value in documenting differences between guidelines and life in the real world.

\section{References}

1. Hannan EL, Samadashvili Z, Smith CR, Lahey SJ, Gold JP, Jordan D, et al. Mitral valve repair versus replacement for patients with preserved left ventricular function without heart failure symptoms. J Thorac Cardiovasc Surg. 2019;157:1432-9.e2. 
2. Enriquez-Sarano M, Suri RM, Clavel MA, Mantovani F, Michelena HI, Pislaru S, et al. Is there an outcome penalty linked to guideline-based indications for valvular surgery? Early and long-term analysis of patients with organic mitral regurgitation. J Thorac Cardiovasc Surg. 2015;150:50-8.
3. Wilkins GT, Weyman AE, Abascal VM, Block PC, Palacios IF. Percutaneous balloon dilatation of the mitral valve: an analysis of echocardiographic variables related to outcome and the mechanism of dilatation. Br Heart J. 1988;60: 299-308. 